Document downloaded from:

http://hdl.handle.net/10251/123466

This paper must be cited as:

Nácher-Soler, VE.; Cáliz, D.; Jaén Martínez, FJ.; Martínez, L. (2018). Examining the Usability of Touch Screen Gestures for Children With Down Syndrome. Interacting with Computers. 30(3):258-272. https://doi.org/10.1093/iwc/iwy011

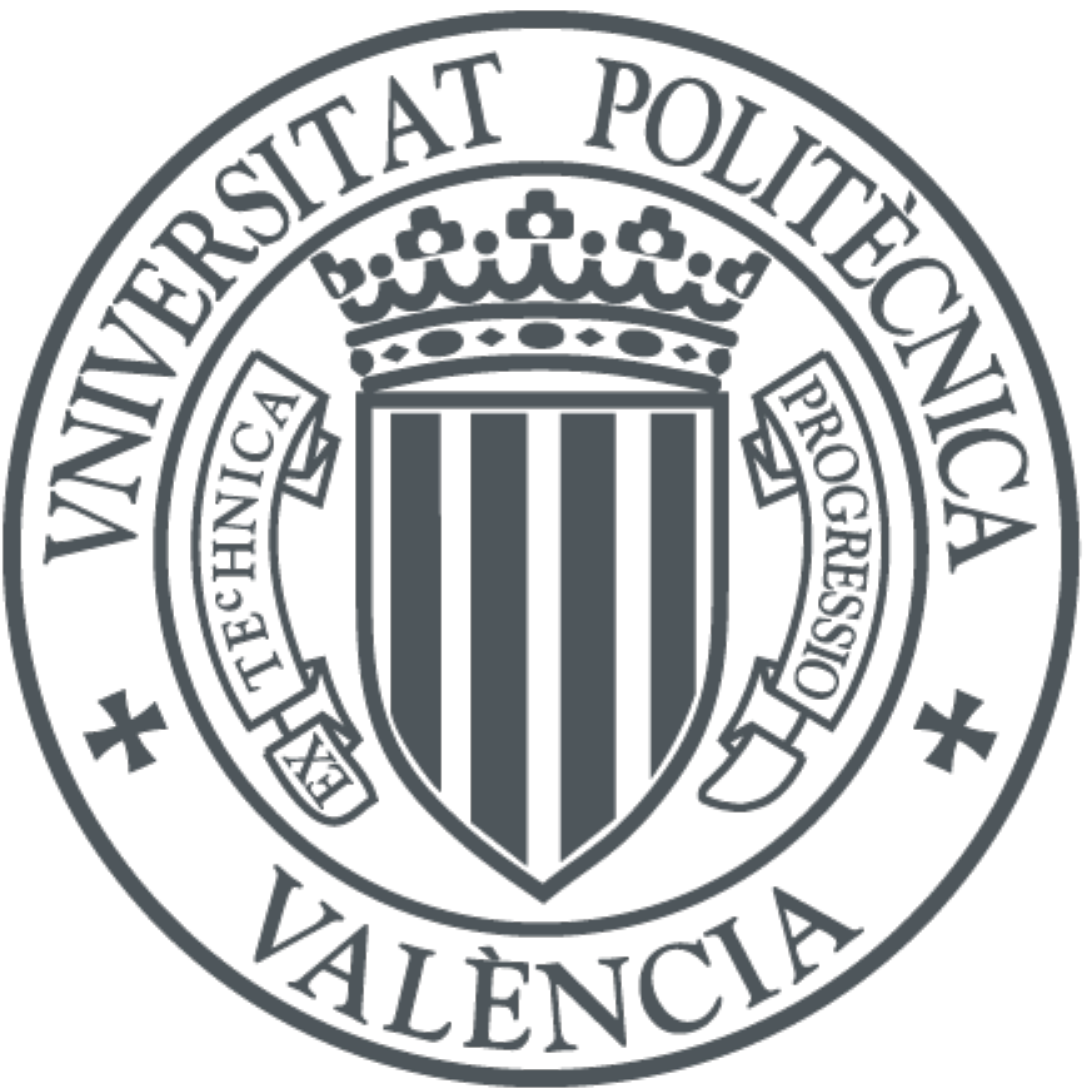

The final publication is available at

http://doi.org/10.1093/iwc/iwy011

Copyright Oxford University Press

Additional Information 


\title{
Examining the Usability of Touch Screen Gestures for Children with Down Syndrome
}

\author{
Vicente Nacher ${ }^{1}$ \\ ISSI Group, Departamento de Sistemas Informáticos y Computación (DSIC), Universitat Politècnica de València \\ Camino de Vera s/n. 46022 Valencia (Spain) \\ vnacher@dsic.upv.es

\section{Doris Cáliz} \\ CETTICO Research group, ETSIINF, Universidad Politécnica de Madrid. \\ Campus de Montegancedo, 28660 Boadilla del Monte, Madrid (Spain) \\ doriscalizramos@outlook.com \\ Javier Jaen
}

ISSI Group, Departamento de Sistemas Informáticos y Computación (DSIC), Universitat Politècnica de València Camino de Vera s/n. 46022 Valencia (Spain)

fjaen@dsic.upv.es

Loïc Martínez

DLSIIS, Facultad de Informática, Universidad Politécnica de Madrid.

CETTICO. PB. Bloque1. Campus de Montegancedo, 28660 Boadilla del Monte, Madrid (Spain)

loic@ fi.upm.es

\footnotetext{
${ }^{1}$ Corresponding author
} 


\section{Acknowledgments}

The authors would like to thank the Maria Corredentora (http://mariacorredentora.org/wpmcorg) and the APADEMA (www.apadema.com) special schools for their collaboration during the carrying out of this study. This work received financial support from Spanish Ministry of Economy and Competitiveness and funded by the European Development Regional Fund (EDRF-FEDER) with the project TIN2014-60077-R (SUPEREMOS). This work was also supported by a pre-doctoral fellowship within the FPU program from the Spanish Ministry of Education, Culture and Sports to V. Nacher (FPU14/00136) and by a pre-doctoral scholarship given by the SENESCYT (Secretaria Nacional de Educación Superior, Ciencia y Tecnología e Innovación) of the government of Ecuador (N0. 381 -2012) to Doris Cáliz. 


\section{Examining the Usability of Touch Screen Gestures for Children with Down Syndrome}

Abstract. The use of multi-touch devices for all types of users (from children to the elderly) has grown considerably in the recent years. However, despite the huge interest in this technology there is a lack of research addressing usability studies on children with Down's Syndrome. This paper evaluates the abilities of these children (aged from 5 to 10 years) when performing a basic set of multi-touch gestures (tap, double tap, long press, drag, scale up \& down, rotation) in tablet devices. The results show that regardless of their more limited motor skills, DS children are able to perform most of the evaluated multi-touch gestures with success rates close to 100 per cent and that this technology could be fully exploited for developing applications targeted specifically at this type of user.

\section{Highlights:}

$>$ Multi-touch technology is used in most emergent devices and is widely accepted

$>$ DS children are able to perform a basic set of multi-touch gestures

$>$ The long-press gesture is not possible by DS children without assistive strategies

$>$ Gender differences are not significant in interaction success rates

Keywords. 1.1.1.2 User studies; 1.1.3.6 Touch screens; 1.2.1.1 User interface design; 1.2.3 Empirical studies in interaction design; 1.4.3.9 Tablet computers; 6.5.2 Interactive learning environments

\section{Introduction}

The use of devices such as tablets, smartphones, consoles and others is changing people's habits (De Haan, 2013)(Peter et al., 2008). Due to this and its more natural and intuitive way of interaction (Smith et al., 2012) multi-touch technology is used in most emergent devices (Johnson et al., 2012), is widely accepted (Buxton, 2013) and young children are confronted with this technology even before oral communicative functions are fully developed (Plowman, 2015). There have been multi-touch usability studies targeted at a range of users from prekindergarten (Nacher et al., 2014) (Vatavu et al., 2015) to adults and the elderly (Gao and Sun, 2015) (Smith and Chaparro, 2015)(Mihajlov et al., 2014). There is thus a clear trend towards using this technology not only by adults but also by children and elderly people. 
Of the potential users of this technology, we are particularly interested in people with Down's Syndrome (DS) because it is unclear how their motor and cognitive development influences their ability to use gesture based interaction. The total number of children born with DS has increased by $31 \%$ since the eighties (Shin et al., 2009) and at present there is one case per 691 births (Parker et al., 2010). People with DS have a cognitive delay (Chapman, 1997) reflected in lower IQ scores in the 40-70 range (Feng et al., 2010) indicating mild to moderate mental impairment (Bull, 2011) and being the intellectual gap with normal children increased with age (Carr, 1985). DS children are affected by three main types of disabilities: cognitive, motor and perceptual (Cohen, 2003), which involves their gross and fine motor skills, their cognitive, linguistic, sensory perception and processing and their communication skills (Abbeduto et al., 2001) (Kumin, 2003). In addition, other areas of development such as social, emotional, communication and self-help skills could be delayed too (Bruni, 2006a). In the specific case of motor skills, they have a retarded neuro-motor development in the first period of life (Vicari, 2006), the motor development is delayed and inharmonic (Pangalos et al., 1994) and the age when children with DS achieve gross motor function is approximately twice the age of a typically developing children (Pueschel, 2009). This is because, as Henderson (1985) points out, reduced explorative behavior can be of importance and neuro-motor system impairments can play a role. Groden (1969) and Hayden (1964) conclude that mentally handicapped children are on average less strong, have less stamina and more problems in the execution of complex motor tasks. They usually have problems with fine motor skills (coordination, manipulation) and problems in eye-hand coordination, dexterity and reaction speed. Moreover, the situation of children with DS is even worse when compared with the children mentally handicapped in other ways. The results of the study by Connolly and Michael (1986) show that the DS children achieve significantly less in terms of the speed of walking, balance, strength, eye-hand coordination and general gross and fine motor abilities making children with DS a special group that deserves a closer attention when considering technologies that require fine motor skills. Regarding the cognitive capabilities of children with DS, their cognitive development is delayed (Weijerman and de Winter, 2010) having lower development in intelligence, attention, verbal communication, learning and memory (Pangalos et al., 1994).

However, taking into account the complexity of designing technologies for children with disabilities, due to their diversity and special needs in their daily lives (Garzotto and Gonella, 2011), there are no usability studies in the literature that explore the suitability of multi-touch gestures for DS children according to their actual cognitive and motor development. This paper evaluates the suitability of a basic set of multi-touch gestures to determine whether DS children from 5 to 10 years old have the required motor skills to be able to use this technology and fully exploit its possibilities. As interfaces for children should be designed according to their development stages and their actual needs (Markopoulos and Bekker, 2003), this work 
addresses the study of these needs to help designers to use good interaction opportunities and develop applications following an inclusive approach that are able to transparently adapt the level of interaction assistance to the actual abilities of the users.

The results of the study suggest that despite their motor issues related to finger and hand movements (including hyper and hyposensitivity to touch) and their difficulty with fine motor movements (Bruni, 2006b), DS children are able to perform a basic set of touch screen gestures with high success rates. They were found to be able to perform properly the tap, double tap, one finger rotation, scale up and scale down gestures. Future applications targeted at them could thus benefit from this wider set of gestures and provide a more enriching interaction when developing multi-touch applications for these users.

\section{Related work}

\section{Studies on fine motor and other skills development}

Many works reviewed in (Lauteslager, 2004) have studied intervention methodologies and defined theoretical frameworks which interpret the motor behavior of DS children providing insight into the specific manner in which the motor development proceeds. However, the focus has been on basic gross-motor skills in early childhood such as motor activity in supine and prone positions, their ability to move forward on the ground, sit on the ground, sit as a transitional posture, stand up or walk.

Other works such as (Memisevic and Macak, 2014) have examined fine motor skills in children with DS in relation to children with other intellectual disabilities and with respect to the child's gender. In this case a Purdue Pegboard Test (a board with two sets of 25 holes positioned vertically requiring the children to put as many pegs as possible in the 25 holes in 30 seconds) was used and their results found no statistically significant differences in both cases. These conclusions are only applicable to children aged 7-15 and only apply to a very basic fine motor interaction which does not involve touch interaction. Other studies have revealed development differences between male and female neuro-typical children in early development such as higher mastery of motor skills in girls (Hardy et al., 2010) (Moser and Reikerås, 2016) or higher performance of boys in spatial tasks (Levine et al., 1999), opening the door to exploration of gender differences in performance.

In the same line of research, the work of Frank and Esbensen (2015) consisted of a crosssectional retrospective chart review with 274 children with DS seen at a specialty clinic that ranged in age from 4 months to 18 years. Specific skills were assessed at occupational therapy assessments as either present or absent, including fine motor, handwriting, scissor usage, selffeeding and clothing management. Their results show that the age range for mastering fine motor and self-care skills broadens as children with DS get older and is in agreement with what is identified in the DS behavioral phenotype with regard to variable motor skills overall. 
However, this study does not address any of the precision activities that are required when using multi-touch devices such as the ones considered in our study.

Finally, there are works for practitioners such as Bruni (2006b) that indicate the importance of developing stability, bilateral coordination, and sensation before children with DS can master finger and hand skills but no recommendations are given with respect to the use of multi-touch technologies to help these children develop these abilities.

Addressing fine-motor skills at a younger age is critical because, as pointed out in (Almeida et al., 2000) (Dulaney and Tomporowski, 2000), data from experimental studies requiring fine motor tasks to be carried out report significant improvement (in both speed and accuracy) in the performance of tasks with practice. This is even more important for children with DS because they require about twice as much practice to reach the same level as typically developing individuals of the same mental age. Therefore, the possible use of technologies to train fine motor skills at early stages of development could result in important benefits for these children.

\section{Uses of technology with DS individuals}

In this respect, the use of technological instruments to help DS individuals develops different types of abilities or to support them during everyday activities has been the focus of extensive efforts. For instance, Lazar et al. (2011) evaluated the abilities of DS adults in terms of workplace-related tasks. Despite there is no evaluation of fine motor skills of the users with DS, the results showed that they are able to use computers for basic work-place tasks such as data entry, word processing and communication using the same keyboard and mouse interfaces as a typical user. In addition, as Feng et al. have pointed out (Feng et al., 2008), more than 70\% of children with DS had started using computers by the age of five and $86.6 \%$ of children use computers at school. Kirijian et al. (2007) presented Web Fun Central, a web application developed specifically for DS teenagers whose main goal was to help teach web browsing and other computer skills. After designing and testing the system with DS teenagers, the authors defined a set of guidelines to be used when designing webs specifically for these users. For example, due to the limited motor skills of people with DS they have several issues when clicking on a small target; hence, the targets need to be bigger when designing applications for them. Another study by Ortega-Tudela and Gomez-Ariza (Ortega-Tudela and Gómez-Ariza, 2006) evaluated how a computer-assisted teaching method can help DS children to learn basic mathematical concepts (counting and cardinality activities). The work compared the computerassisted strategy with a paper-based learning method and the results showed that the first group performed better showing that the visual help offered by the computer facilitated the perception and ability to process information of children with DS. Hence, this type of strategies could fit the special needs of these children more than the traditional pencil and paper-based. Brandao et al. (Brandão et al., 2010) evaluated the way in which DS children interacted when playing computer games and found that these games are not suitable for the actual needs of these 
children. Hence, the authors developed their own computer game that stimulates a set of cognitive activities such as imitation, perception, fine motor skills, hand-eye coordination and receptive and expressive verbal language. This game was evaluated with a group of DS children who were able to complete all the proposed activities correctly. Following the same line, Haro et al. (2012) developed a pedagogical approach to teach reading and writing to DS children using a book augmented with tangible interfaces in tablets and tabletops. The results of the experiment showed that children were motivated when using the system and stayed focused on the learning activities. Nevertheless, this work did not use any kind of multi-touch interaction, since the children used tangible elements to interact with the devices. The studies listed above show that people with DS can take advantage of the new technologies when designers develop tailored interfaces to their abilities. However, they do not include multi-touch technology and so the interaction of DS subjects with touch screen devices has not been evaluated.

Multi-touch technology studies

One of the few existing studies on DS people using multi-touch technology is the work by Kumin and Lazar (2012), who evaluated the usability of workplace-related tasks using tablet devices with DS adults. Their results showed that all the participants completed most of the tasks and DS adults interacted with the touchscreen surface in a similar way to neuro-typical users. Few works can be found in the literature focused on the use of multi-touch devices by DS children. Jadan-Guerrero et al. (2015) presented the Kiteracy framework to help in literacy learning. They compared three interaction methodologies; cardboard, multi-touch and tangible and their results showed that in the traditional cardboard approach the teachers take control of the activity, in the tangible approach children take control and in the multi-touch approach the control is shared by the children and teachers. In the self-learning sessions evaluated, the authors observed that the multi-touch and tangible approaches are more enjoyable for children. Finally, the use of the framework offered advantages for literacy skills since the interaction between children and teachers increased respect to the traditional approach.

Other interesting studies can be found addressing the use of touch devices by children with other types of cognitive disorders such as Asperger's Syndrome and Autism Spectrum Disorder (ASD) (Hourcade et al., 2011) (Piper et al., 2006) (Rubio et al., 2012) (Weiss et al., 2011) (Fernández-López et al., 2013). These works obtained positive results in terms of collaboration and motivation. However, they did not study the usability of multi-touch gestures and did not use DS children as subjects, so that their results cannot be extrapolated to DS users.

Table 1. Studies in the literature addressing the use of new technologies by DS subjects.

\begin{tabular}{l|l|l|l|l}
\hline Study & $\begin{array}{l}\text { Users } \\
\text { tested }\end{array}$ & $\begin{array}{l}\text { Age } \\
\text { (years) }\end{array}$ & Scope & Apparatus \\
\hline Lazar et al (2011) & 10 & $22-38$ & $\begin{array}{l}\text { Examine the workplace-related } \\
\text { computer skills of expert users }\end{array}$ & Computer \\
\hline
\end{tabular}




\begin{tabular}{l|l|l|l|l}
\hline Kirijian et al (2007) & 6 & $16-23$ & $\begin{array}{l}\text { Evaluate a web design and } \\
\text { propose guidelines }\end{array}$ & Computer \\
\hline $\begin{array}{l}\text { Ortega-Tudela \& } \\
\text { Gómez-Ariza (2006) }\end{array}$ & 23 & $4-8$ & $\begin{array}{l}\text { Evaluate an app to learn basic } \\
\text { mathematical concepts }\end{array}$ & Computer \\
\hline Brandão et al (2010) & Unknown & $3-7$ & $\begin{array}{l}\text { Test a game that stimulates } \\
\text { cognitive areas }\end{array}$ & Computer \\
\hline Kumin \& Lazar (2012) & 10 & $19-29$ & $\begin{array}{l}\text { Examine the usability of tablets } \\
\text { for workplace-related tasks }\end{array}$ & Tablet \\
\hline $\begin{array}{l}\text { Jadan-Guerrero et al } \\
\text { (2015) }\end{array}$ & 12 & $4-8$ & $\begin{array}{l}\text { Compare cardboard, multi- } \\
\text { touch and tangible interaction }\end{array}$ & Tablet \\
\hline $\begin{array}{l}\text { (Haro et al., 2012) } \\
\text { (Aziz et al., 2015) }\end{array}$ & 3 & $\begin{array}{l}\text { A kid, } \\
\text { teenager } \\
\&\end{array}$ & $\begin{array}{l}\text { Evaluate a technological } \\
\text { strategy based on a book } \\
\text { augmented with tangible } \\
\text { interfaces to develop reading }\end{array}$ & $\begin{array}{l}\text { Tablet/Tableto } \\
\text { young }\end{array}$ \\
\hline $\begin{array}{l}\text { (Reis \& Margarida, } \\
\text { 2015) }\end{array}$ & 1 & Unknown & $\begin{array}{l}\text { Evaluate the usage of a mobile } \\
\text { numerical application }\end{array}$ & Smartphone \\
\hline The present study & 55 & $5-10$ & $\begin{array}{l}\text { Sung press, drag, scale up, scale } \\
\text { down and one finger rotation } \\
\text { gestures) }\end{array}$ & Tablet \\
\hline
\end{tabular}

Multi-touch technology avoids the problems of using mediated devices, such as mouse, keyboard or joystick, and enables users to take advantage of the direct manipulation interaction and the benefits of direct touch. As far as we know, the existing studies on DS subjects only evaluated small groups of users (see Table 1). Moreover, there are no existing studies that address the usability of multi-touch gestures by DS children. The few works that do exist do not focus on gesture usability and do not explore suitability of the gestures according to the actual cognitive and motor development of children with DS, but evaluate an application which did not involve a complete set of multi-touch gestures. Therefore, the aim of the present study is to evaluate the actual capabilities of DS children when using multi-touch technology and to find out which gestures are suitable for them as it has already been studied with typically developing children with gestures of different cognitive complexity level (Nacher et al., 2015) (Vatavu et al., 2015).

\section{Experimental Study}

The overall goal of our study was to investigate the suitability of a basic set of multi-touch gestures for DS children. Using the GQM (Goal Question Metric) template (Basili et al., 1994), it could be defined as follows: analyze a set of multi-touch gestures for the purpose of 
evaluating their suitability from the viewpoint of usability in multi-touch technologies in the context of DS children.

For this study, DS children of both genders aged between 5 and 10 years old were considered. In order to find out to what extent different levels of motor cognitive development have an impact on their ability to interact with multi-touch devices and given that age is a main factor in other studies that analyze motor and cognitive skills development in children with DS (Malak et al., 2013) (Wishart, 1993), participants were divided into two groups: children from 5 to 7 and from 8 to 10. According to (Piaget, 1973), children in the first age group are in the final phase of the preoperational stage and those in the older age group are in the concrete operational stage. The performance of the two groups was analyzed to find any differences between them. In addition, as stated above, development differences have been reported between male and female neuro-typical children in early development, making gender another focus of interest in our study. Hence, the participants were also balanced in terms of this factor. As a result, Gender and Age group were the two main independent variables considered. The Completion time and the Success rate were the two measured dependent variables for each task (tap, double tap, long press, drag, scale up, scale down, one-finger rotation). Moreover, an observer wrote down the usability issues that happened along the tasks in order to have qualitative data about the interactions.

The following alternative hypotheses were defined:

- $\mathrm{H}_{1 \mathrm{~A}}$ : The task has an effect on the degree of success

- $\mathrm{H}_{1 \mathrm{~B}}$ : The task has an effect on the completion time

- $\mathrm{H}_{1 \mathrm{C}}$ : Gender has an effect on the success rate of task $k$

- $\mathrm{H}_{1 \mathrm{D}}$ : Age has an effect on the success rate of task $k$

- $\mathrm{H}_{1 \mathrm{E}}$ : Gender has an effect on the completion time of task $k$

- $\mathrm{H}_{1 \mathrm{~F}}$ : Age has an effect on the completion time of task $k$

The corresponding null hypotheses for the alternative hypotheses listed above will be: $\mathrm{H}_{0 \mathrm{i}}=\neg \mathrm{H}_{1 \mathrm{i}}$ The first two hypotheses were related to the homogeneity of the success rates and completion times of the different tasks and the other four were defined for each task performed (type of gesture).

\subsection{Participants}

In order to answer the research questions listed above, fifty-five DS children aged between 5 and 10 years took part in the experiment $($ Mean $(M)=6.67$, Standard Deviation $(S D)=1.50)$. The genders of the participants were balanced, with 30 males and 25 females. The children were divided in two age groups: 5 to 7 years (12 males and 12 females), 8 to 10 years (18 males and 13 females). The children involved in the experiment were from special centers for DS children. These centers apply personalized and individualized educational methodologies to help DS 
children develop new cognitive and motor skills. All children had previous experience using parental smartphones.

\subsection{Equipment}

The interaction framework for the experiment was implemented in Java using JMonkeyEngine SDK v.3.0beta. The device used for deployment and the experiment was a Szenio 10.1 tablet with Android 4.2 with a capacitive multi-touch screen with a resolution of $1024 \times 600$ pixels.

\subsection{Procedure}

For each task, the children were accompanied by an instructor for up to-5-minutes to understand the gestures to be performed. If they understood the tasks before the 5 minutes, the task began at that moment. The experimental platform then asked them to perform the task without any assistance (see Figure 1). They had to perform three repetitions of each gesture under specific conditions (see Tasks section). Different images of animals were used in the tasks having all of them the same size $(5 \times 5 \mathrm{~cm})$. When the gesture was completed successfully, the platform gave a positive audiovisual feedback. If the instructor saw that the participant did not carry out the task in a given time, it was marked as undone and the child went on to the next one.

For each interaction, the system recorded the start time (seconds needed to go into action after the visual stimulus was shown), completion time, success (performed correctly or incorrectly), and the number of contacts with the surface (in order to know in an unsuccessful action whether the user had made any attempt to interact). A qualitative analysis was also carried out from the notes taken by an external observer during the experimental sessions. The observer writes down the children' behaviors while they are performing a task and, after the session, aggregates the data in order to have a count of the times that a behavior occurs. Hence, the aggregated data could be reported and discussed in order to understand and explain possible usability issues. 


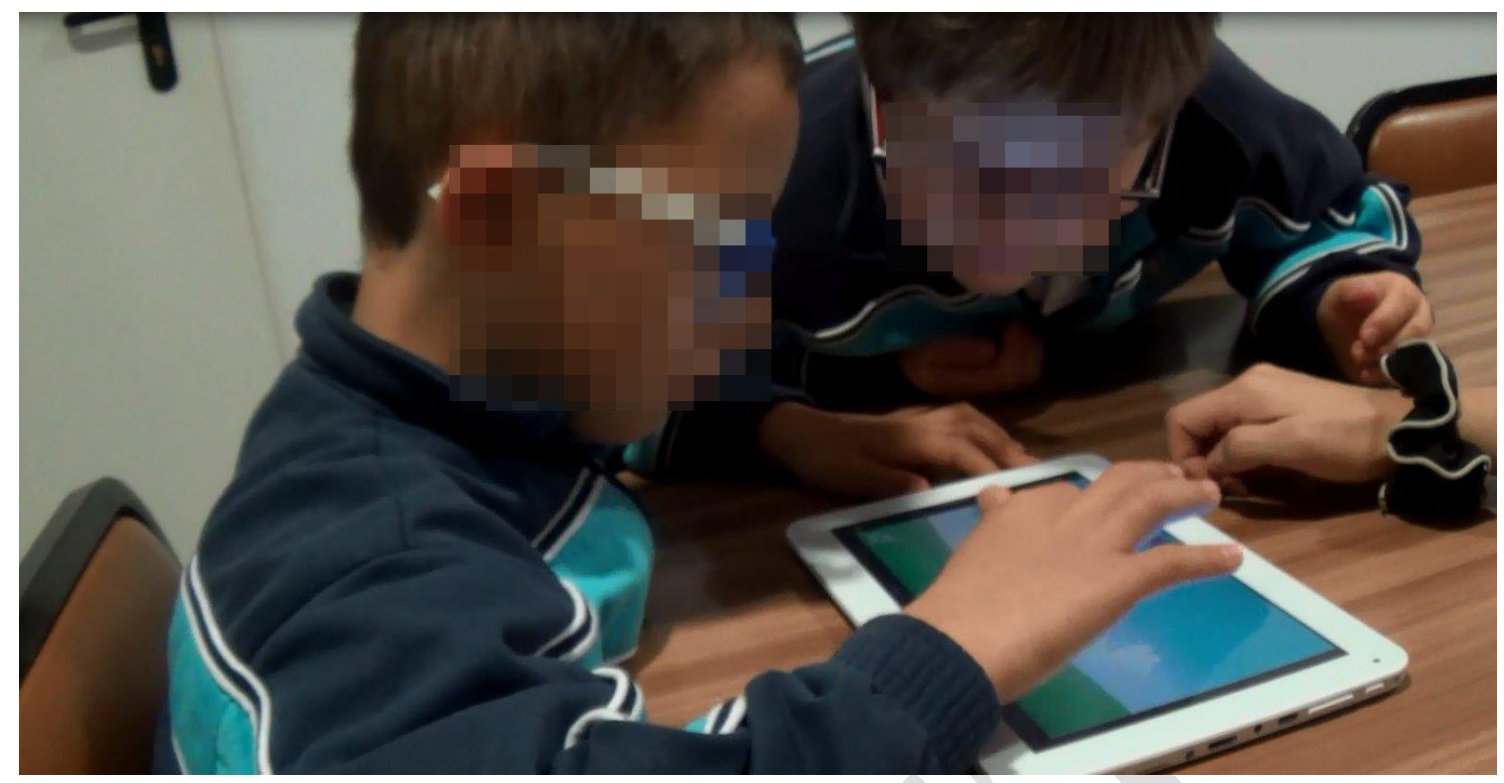

Figure 1. Children taking part in the experiment.

\section{Tasks}

\subsection{Task 1: Tap}

A static image of an animal appears in a random position on the screen (see Figure 2), and participants are requested to tap on the target image in order to pass the test.

\subsection{Task 2: Double Tap}

A static image of an animal appears in a random position on the screen (see Figure 2). Participants are requested to double tap on the target image with one finger in order to pass the test. The task will succeed when the participants perform two taps in under 300 milliseconds, which is Android's default time interval for this gesture.

\subsection{Task 3: Long Press}

A static image of an animal appears in a random position on the screen (see Figure 2). Participants are requested to carry out a long pressed gesture on the target image until the target disappears. The task will succeed when the participants put their finger on the target image and hold it for at least 500 milliseconds, which corresponds to the Android's default time interval for this gesture. 


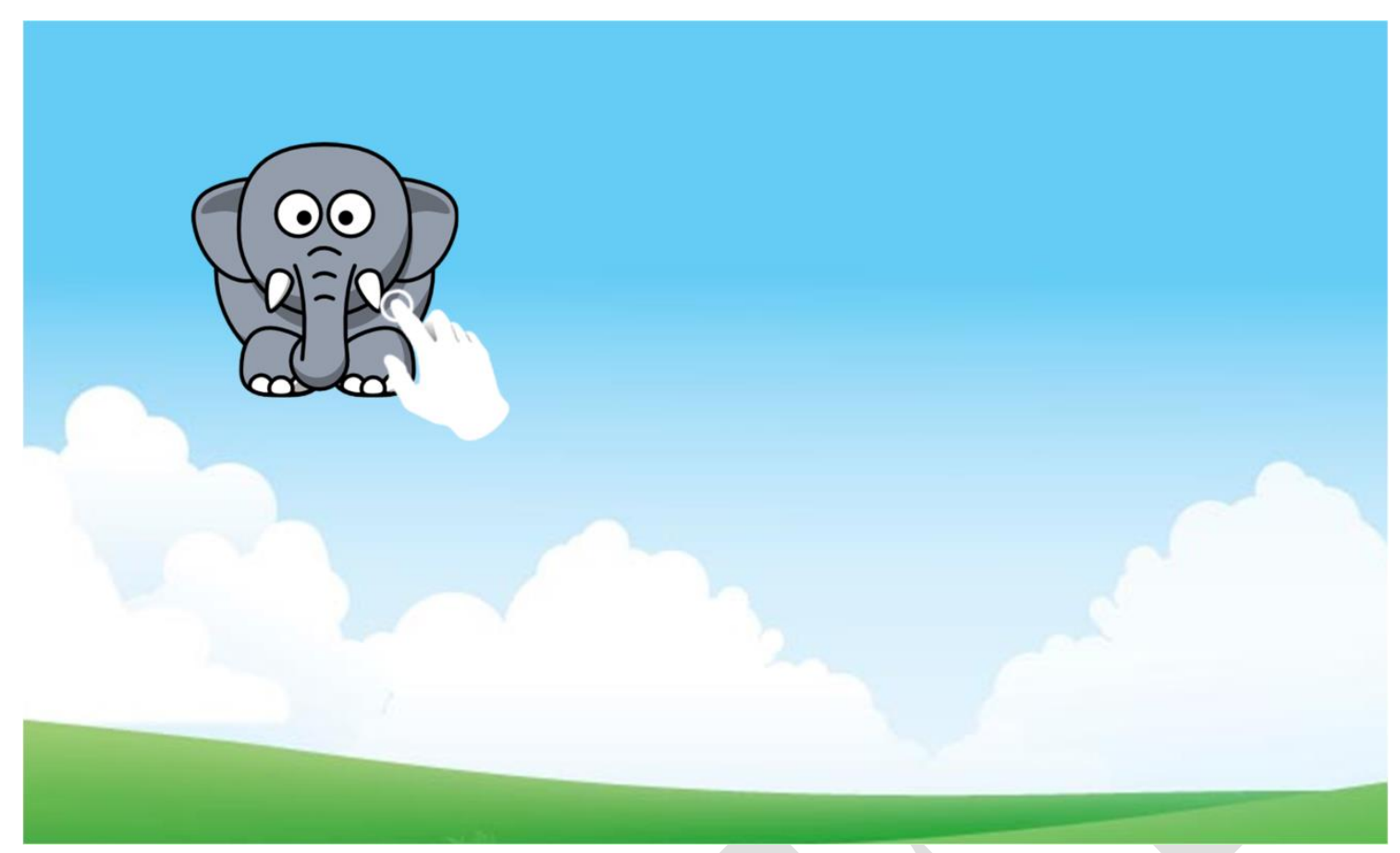

Figure 2. Example of a simple tap, double tap or long pressed test.

\subsection{Task 4: Drag}

A static image of an animal appears in a random position on the screen and the same (reference) image appears in a white profile in another random position, always at a distance of 378 pixels so as to be able to compare execution times among the different subjects (see Figure 3 ). The random position of the reference image is subject to some geometric restrictions, to make sure that it is completely visible on the surface. Participants are requested to drag the target to the reference image with one finger. The task will succeed when the target image reaches the location of the reference image with a precision of less than 10 pixels on each $\mathrm{X}$ and $\mathrm{Y}$ axis. It is not necessary for the subject to lift his/her hand to reach success. 


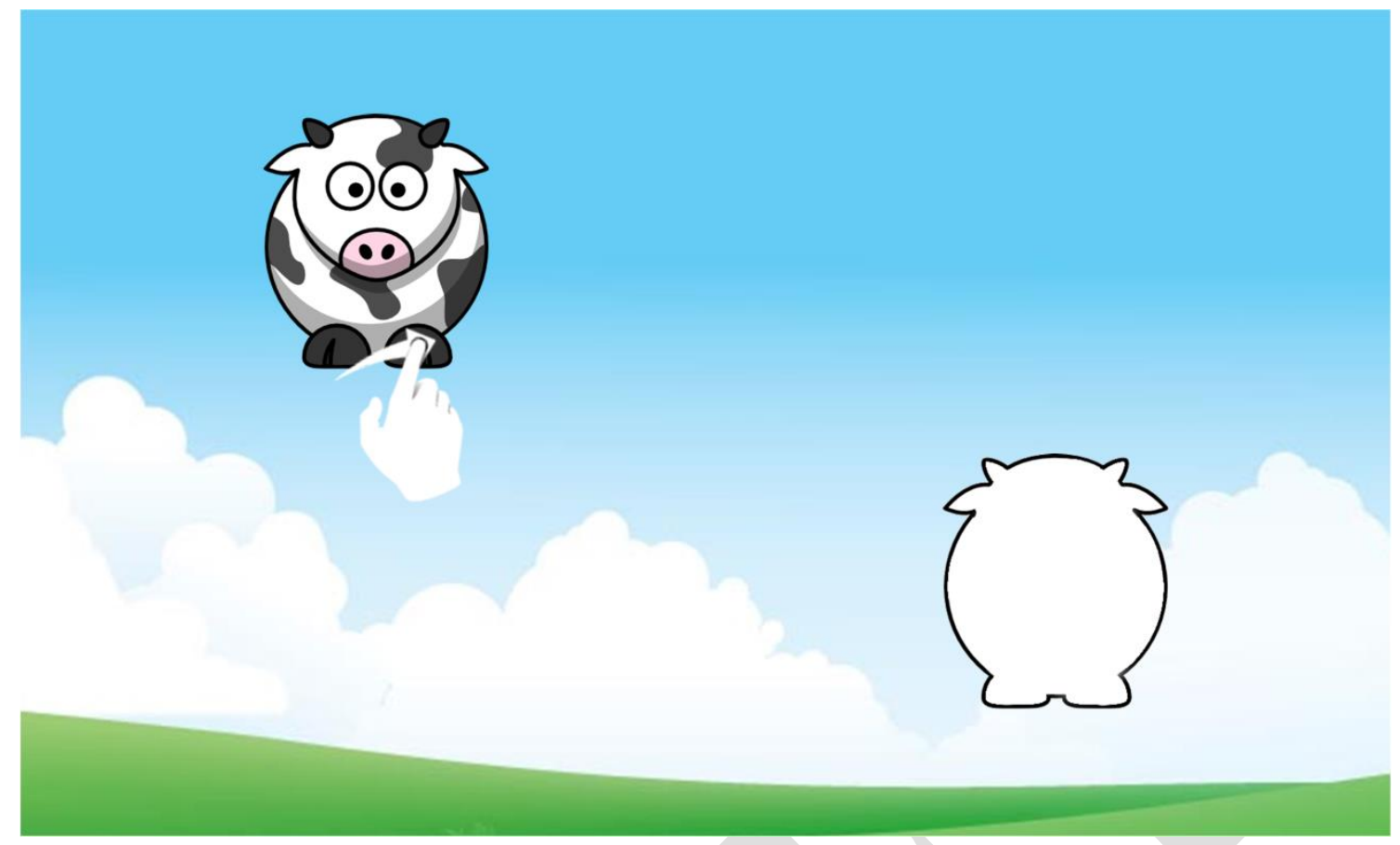

Figure 3. Example of a drag test.

\subsection{Task 5: Scale up}

A static image of an animal appears in the center of the screen within a similar but 1.5 times larger reference shape (see Figure 4-a). Participants are requested to scale up the target image to the size of the reference shape. This can be done by expanding the distance between two fingers of either one hand or two hands. The fingers do not have to be in contact with the reference image and the scaling factor applied is the incremental value returned by the JMonkeyEngine runtime for this gesture. If more than two contacts are made on the surface, JMonkeyEngine considers only the two most recent ones for communicating scaling events. The task will succeed when the target image reaches the size of the reference image, and it is not necessary for the subject to lift his/her hands when the correct size is reached.

\subsection{Task 6: Scale down}

A static image of an animal appears in the center of the screen superimposed on a similar reference shape half its size (see Figure 4-b). Participants are requested to scale down the target image by making the target object shrink until it reaches the size of the reference image with two fingers of either one or two hands. The task will succeed when the target image reaches the size of the reference image, as in the previous case. 


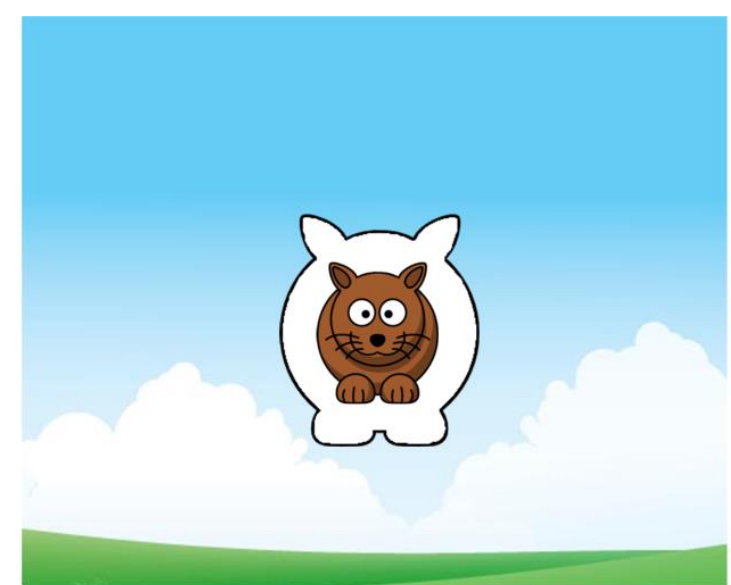

(a)

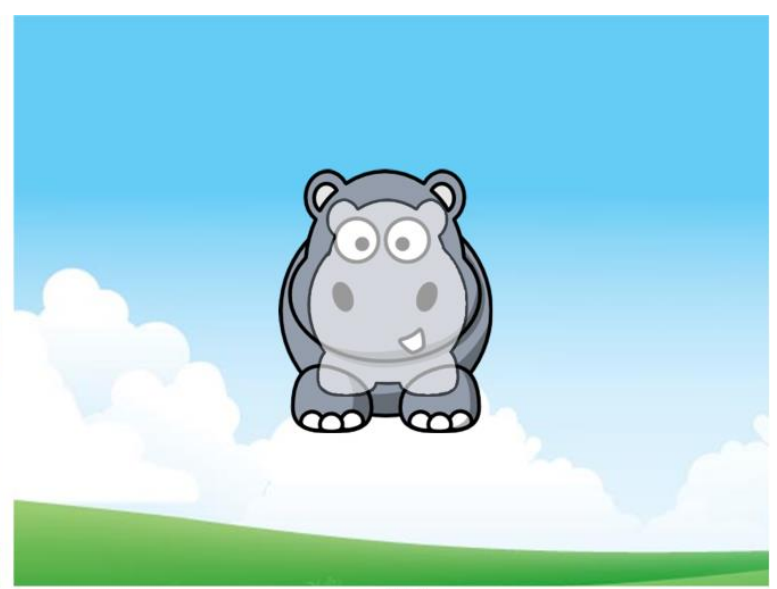

(b)

Figure 4. Example of a scale test: (a) scale up (b) scale down.

\subsection{Task: One-finger rotation}

A static image of an animal appears in the center of the screen in front of a blank profile of the same image in a different orientation. Rotation is always clockwise to a fixed position so as to be able to compare interaction execution times among subjects (see Figure 5). Participants are requested to rotate the target image to the position of the reference image by dragging one finger around the center of the target image. Pressure can be applied on the target image itself or anywhere around it. The task will succeed when the target image reaches an angle larger than the specified goal, which is automatically detected by the system to provide positive audiovisual feedback.

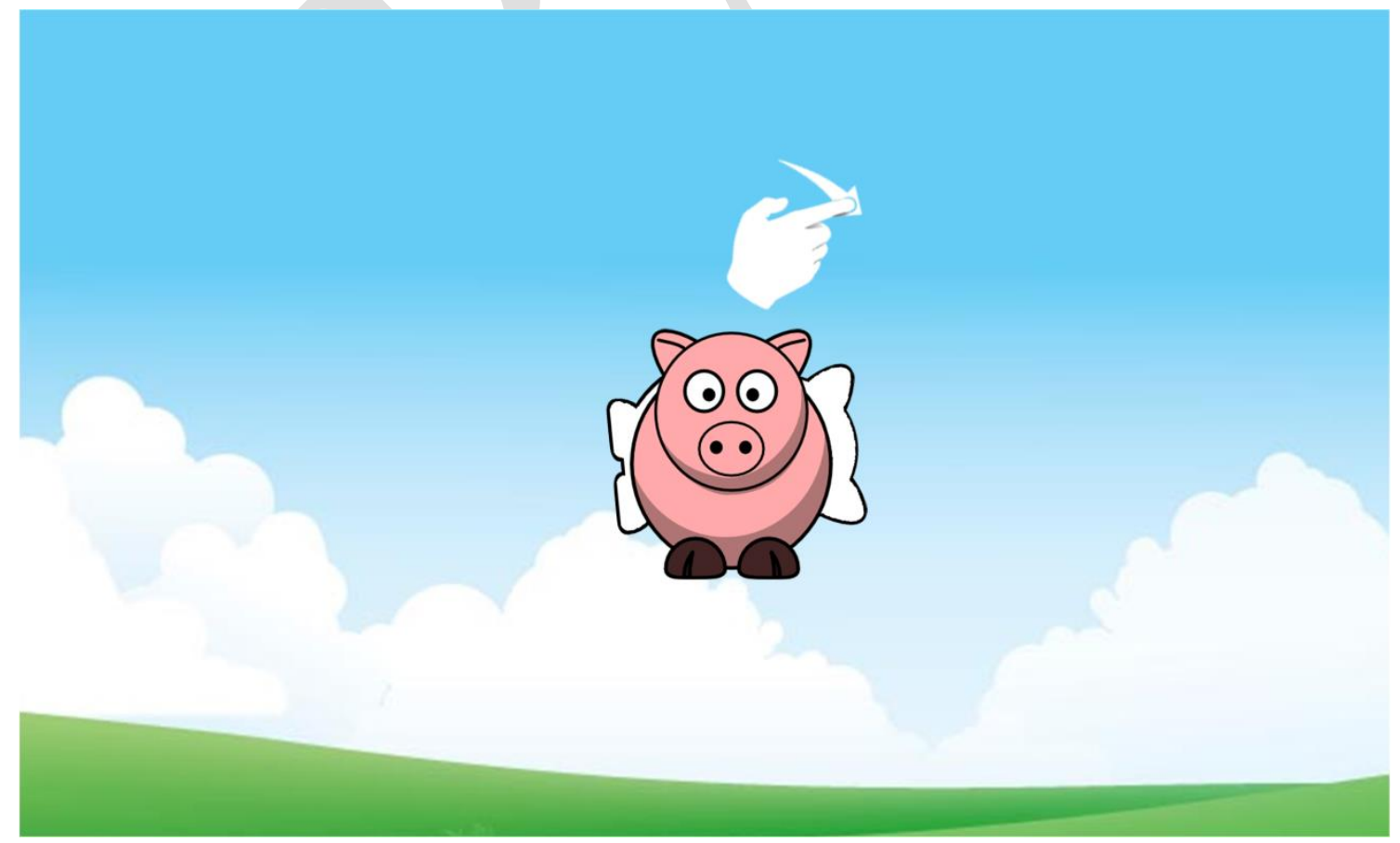

Figure 5. Example of a One-Finger rotation test. 


\section{$5 \quad$ Results}

In this section, the results of the experimental tests are presented according to each of the analyzed independent variables. First of all, the tasks are compared in Section 5.1, then the completion time is addressed in Section 5.2 and the success rate is explored in Section 5.3.

\subsection{Task comparison}

The three tests carried out by each participant for each task were also combined in order to depict the success as a percentage. If a participant performed successfully either zero or one tests in a specific task, he (she) was considered incapable of performing it, whereas if they successfully performed two or three tests in a specific task, they were considered capable of doing it, as they actually showed their ability to consistently reproduce the gesture several times. According to this codification the success rate for each task is shown in Figure 6, in which it can be seen that, except for long press, all the tasks were performed with nearly a $100 \%$ of success rate.

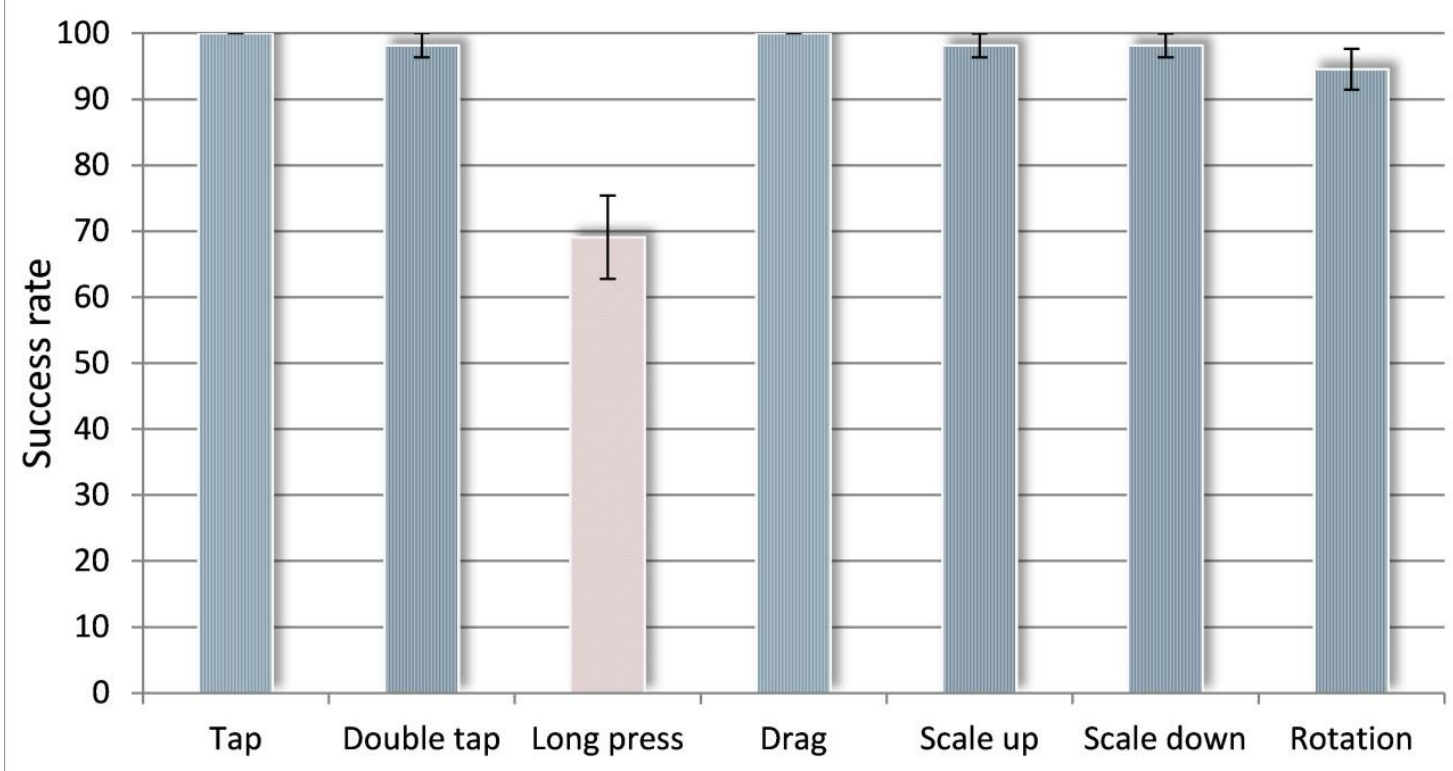

Figure 6. Success rate by task.

A pair-wise task comparison was conducted to test whether degree of success was independent of task. A Pearson's chi-square test of independence was used. A Bonferroni correction that establishes statistical significance at $p<0.05 / 21=0.00238$ has been applied due to the large number of comparisons (21 hypotheses). Table 2 shows the results of the statistical analysis. Each cell contains the significance obtained from the analysis of each pair of tasks $\left(^{*}\right.$, $\mathrm{p}<0.00238 ; * *, \mathrm{p}<0.001)$. 
Table 2. Task comparison by success with Pearson's chi-square test of independence $\chi^{2}$ $(\mathrm{DoF}=1, \mathrm{~N}=55)$

\begin{tabular}{l|r|r|r|l|l|l|l}
\hline Success & Tap & $\begin{array}{r}\text { Double } \\
\text { Tap }\end{array}$ & $\begin{array}{r}\text { Long } \\
\text { Press }\end{array}$ & Drag & $\begin{array}{r}\text { Scale } \\
\text { Up }\end{array}$ & $\begin{array}{r}\text { Scale } \\
\text { Down }\end{array}$ & $\begin{array}{l}\text { Rofinger } \\
\text { Rotation }\end{array}$ \\
\hline Tap & & 0.315 & $0.000 * *$ & 1.000 & 0.315 & 0.315 & 0.079 \\
\hline Double Tap & & & $0.000 * *$ & 0.315 & 1.000 & 1.000 & 0.308 \\
\hline Long Pressed & & & & $0.000 * *$ & $0.000 * *$ & $0.000 * *$ & $0.001 *$ \\
\hline Drag & & & & & 0.315 & 0.315 & 0.079 \\
\hline Scale Up & & & & & & 1.000 & 0.308 \\
\hline Scale Down & & & & & & & 0.308 \\
\hline
\end{tabular}

As can be seen in Figure 6, the results in Table 2 showed that not all the gestures had the same success rates; hence $\mathrm{H}_{1 \mathrm{~A}}$ is accepted. According to the statistical tests, the success rate for the long press gesture is significantly lower (around 70 per cent) than that of the remaining tasks (tap, double tap, drag, scale up, scale down and one-finger rotation) in which the children achieved similar success rates (around 100 per cent).

The variance in completion time of each task is presented in Table 3 and was also analyzed.

Table 3. Variance of completion time (in seconds) by task

\begin{tabular}{l|l|l}
\hline \multicolumn{2}{|c}{} & Variance \\
\hline \multirow{4}{*}{ Task } & Tap & 3.15 \\
\cline { 2 - 3 } & Double Tap & 6.57 \\
\cline { 2 - 3 } & Long Press & 15.66 \\
\cline { 2 - 3 } & Drag & 3.81 \\
\cline { 2 - 3 } & Scale Up & 33.70 \\
\cline { 2 - 3 } & Scale Down & 15.96 \\
\cline { 2 - 3 } & One-Finger Rotation & 10.77 \\
\hline
\end{tabular}

Table 4 shows Levene's test for the homogeneity of variance in the completion time when comparing the tasks. Each cell contains the significance of a combination of two tasks. In this case $\chi^{2}(\operatorname{DoF}($ Task X, Task $Y)=\operatorname{DoF}($ Task X) $+\operatorname{DoF}($ Task $Y)-2$ (see Table 5 for the DoF values of each task). Given the large number of comparisons (a family of $m=21$ hypotheses) we applied a Bonferroni correction that establishes statistical significance at $\mathrm{p}<0.05 / 21=0.00238$.

Table 4. Results of Levene's test $\left(^{*}, \mathrm{p}<0.00238 ;{ }^{* *}, \mathrm{p}<0.001\right)$.

\begin{tabular}{l|r|r|r|r|l|l|l}
\hline Success & Tap & $\begin{array}{r}\text { Double } \\
\text { Tap }\end{array}$ & $\begin{array}{r}\text { Long } \\
\text { Press }\end{array}$ & Drag & Scale Up & $\begin{array}{r}\text { Scale } \\
\text { Down }\end{array}$ & $\begin{array}{l}\text { 1-Finger } \\
\text { Rotation }\end{array}$ \\
\hline Tap & & 0.102 & $0.000^{* *}$ & 0.946 & $0.016^{*}$ & $0.000^{* *}$ & $0.000^{* *}$ \\
\hline Double Tap & & & $0.005^{*}$ & 0.135 & 0.102 & $0.001^{*}$ & $0.009^{*}$ \\
\hline Long Pressed & & & & $0.000^{* *}$ & 0.917 & 0.678 & 0.479 \\
\hline Drag & & & & & $0.018^{*}$ & $0.000^{* *}$ & $0.000^{* *}$ \\
\hline Scale Up & & & & & & 0.704 & 0.751 \\
\hline Scale Down & & & & & & & 0.211 \\
\hline
\end{tabular}

According to the results of the analysis shown in Table $4, \mathrm{H}_{1 \mathrm{~B}}$ is accepted since the variance in the children's completion time is not the same for all the evaluated gestures. The analysis 
showed that two groups of gestures are opposed in terms of the level of variance in children's completion time. The Tap and Drag gestures are the ones with the lowest level of variance, i.e. the results are homogeneous in terms of completion time for these gestures. These gestures resulted significantly different in terms of variance from another group of gestures composed by the Scale Down and One-Finger Rotation which have a higher level of variance revealing that the completion times are more disperse and there are some differences between the subjects when performing the task. Finally, there is another set of gestures between these two extremes in which the statistical analysis does not reveal enough significances to define a well delimited group.

\subsection{Completion time}

In order to aggregate the data per participant and task, the three trials carried out by each one per gesture were combined. The average of each subject's successful tasks was used to obtain the average completion time value per task and user. If the test was not performed successfully it was not included in the completion time analysis, resulting in different statistical degrees of freedom for each task. The mean completion time for each task by age group and gender is given in Table 8 and Table 9 (see Appendix A).

A two-way between-subject ANOVA with the independent variables gender and age group and dependent variable completion time was applied. The statistical analysis (Table 5) demonstrated that age and gender have no significant effect on the completion time in any of the tasks. Hence, the hypotheses $\mathrm{H}_{1 \mathrm{E}}$ and $\mathrm{H}_{1 \mathrm{~F}}$ cannot be accepted according to the conducted tests.

Table 5. F-Statistics of the completion time analysis

\begin{tabular}{l|c|c|c|c|c|c|c}
\hline \multirow{2}{*}{ Task } & \multirow{2}{*}{ DoF } & \multicolumn{2}{c|}{ Gender } & \multicolumn{2}{c|}{ Age group } & \multicolumn{2}{c}{ Gender*Age } \\
\cline { 3 - 8 } & & F & p-value & F & p-value & F & p-value \\
\hline Tap & $(1.55)$ & 1.861 & 0.179 & 0.043 & 0.836 & 0.119 & 0.732 \\
\hline Double Tap & $(1.55)$ & 0.545 & 0.464 & 0.081 & 0.777 & 5.478 & 0.023 \\
\hline Long Press & $(1.48)$ & 0.455 & 0.504 & 0.520 & 0.475 & 0.980 & 0.328 \\
\hline Drag & $(1.55)$ & 1.834 & 0.182 & 0.620 & 0.435 & 2.097 & 0.154 \\
\hline Scale Up & $(1.55)$ & 1.009 & 0.320 & 0.781 & 0.381 & 0.006 & 0.940 \\
\hline Scale Down & $(1.54)$ & 0.229 & 0.635 & 1.040 & 0.313 & 0.916 & 0.343 \\
\hline One-Finger Rotation & $(1.55)$ & 1.406 & 0.241 & 1.099 & 0.300 & 2.131 & 0.151 \\
\hline
\end{tabular}

\subsection{Success rate}

In order to obtain one value per user and task, the success data was combined as detailed in the Task comparison section. The resulting success rate of each task is shown in Table 10 and Table 11 in the Appendix A. The success rate by task and age group is shown graphically in Figure 7. 


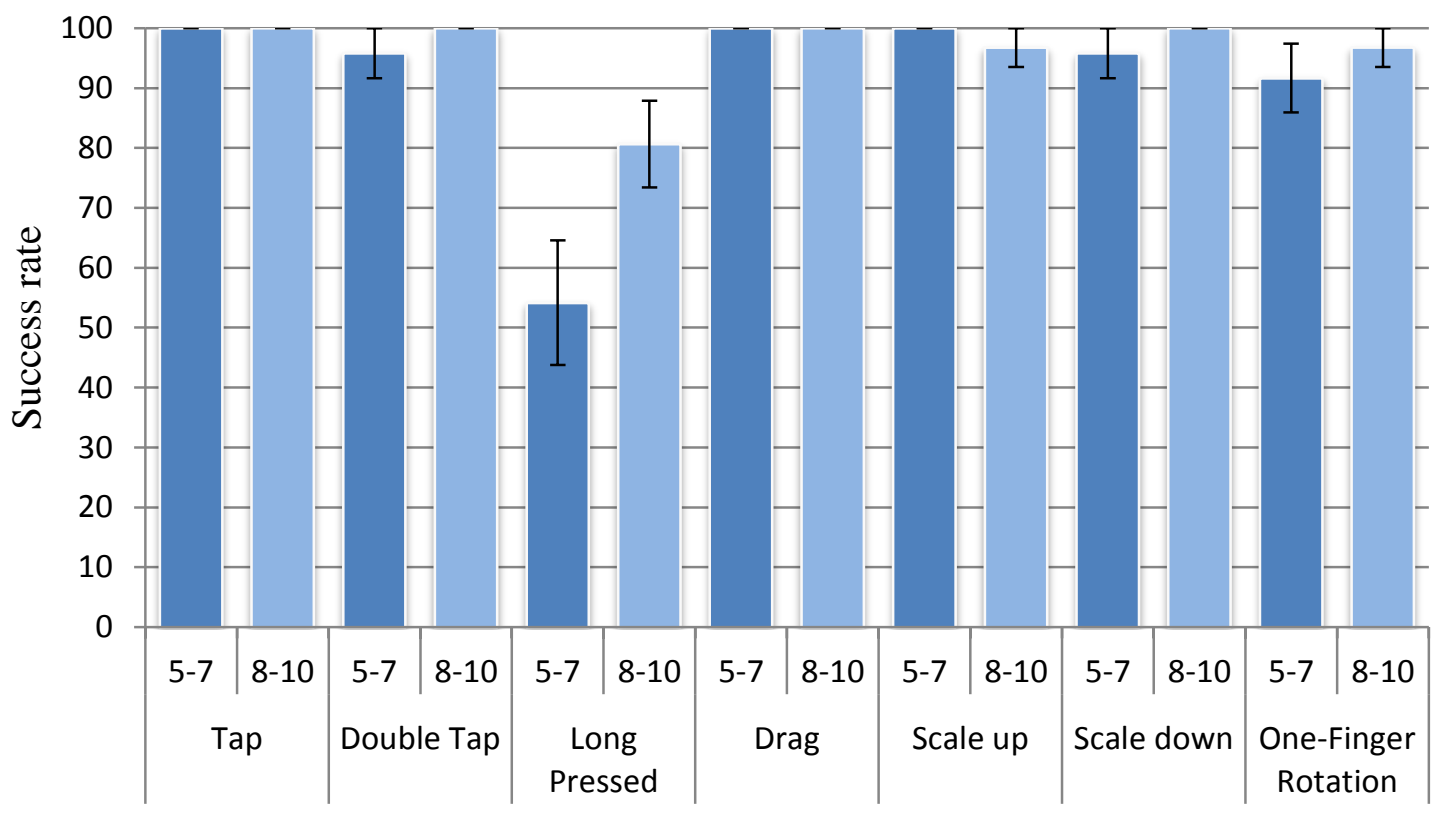

Figure 7. Success rate by task and age group.

Pearson's chi-square tests were conducted on each gesture to determine the independence of success from two qualitative factors (gender and age group). $\mathrm{H}_{1 \mathrm{D}}$ cannot be accepted for most of the tasks since the tests showed that age has no effect on the degree of success for the Tap, Double Tap, Drag, Scale Up, Scale Down and One-Finger Rotation tasks (see Table 6). However, the results are in support of $\mathrm{H}_{1 \mathrm{D}}$ and it is accepted in the Long Press task because the older age group performed the task with a significantly higher success rate than the younger group.

Table 6. Statistics of Pearson's chi-square test

\begin{tabular}{l|l|l|l|l|l|l|l|l}
\hline \multirow{2}{*}{ Task } & \multirow{2}{*}{ DoF } & \multicolumn{2}{l}{ Gender } & \multicolumn{2}{l}{ Age group } & \multirow{2}{*}{ DoF } & \multicolumn{2}{l}{ Gender*Age group } \\
\cline { 3 - 9 } & & $\chi^{2}$ & p-value & $\chi^{2}$ & p-value & & $\chi^{2}$ & p-value \\
\hline Tap & 1 & 0.000 & 1.000 & 0.000 & 1.000 & 3 & 0.000 & 1.000 \\
\hline Double Tap & 1 & 1.222 & 0.269 & 1.316 & 0.251 & 3 & 3.650 & 0.302 \\
\hline Long Press & 1 & 0.182 & 0.670 & 4.441 & 0.035 & 3 & 4.801 & 0.187 \\
\hline Drag & 1 & 0.000 & 1.000 & 0.000 & 1.000 & 3 & 0.000 & 1.000 \\
\hline Scale Up & 1 & 0.849 & 0.357 & 0.789 & 0.375 & 3 & 2.094 & 0.553 \\
\hline Scale Down & 1 & 0.849 & 0.357 & 1.316 & 0.251 & 3 & 3.650 & 0.302 \\
\hline One-Finger Rotation & 1 & 0.576 & 0.448 & 0.684 & 0.408 & 3 & 1.550 & 0.671 \\
\hline
\end{tabular}

Regarding the gender factor, the analysis revealed that gender has no effect on the degree of success in any of the tasks (see Table 6). Hence, $\mathrm{H}_{1 \mathrm{C}}$ is rejected. 


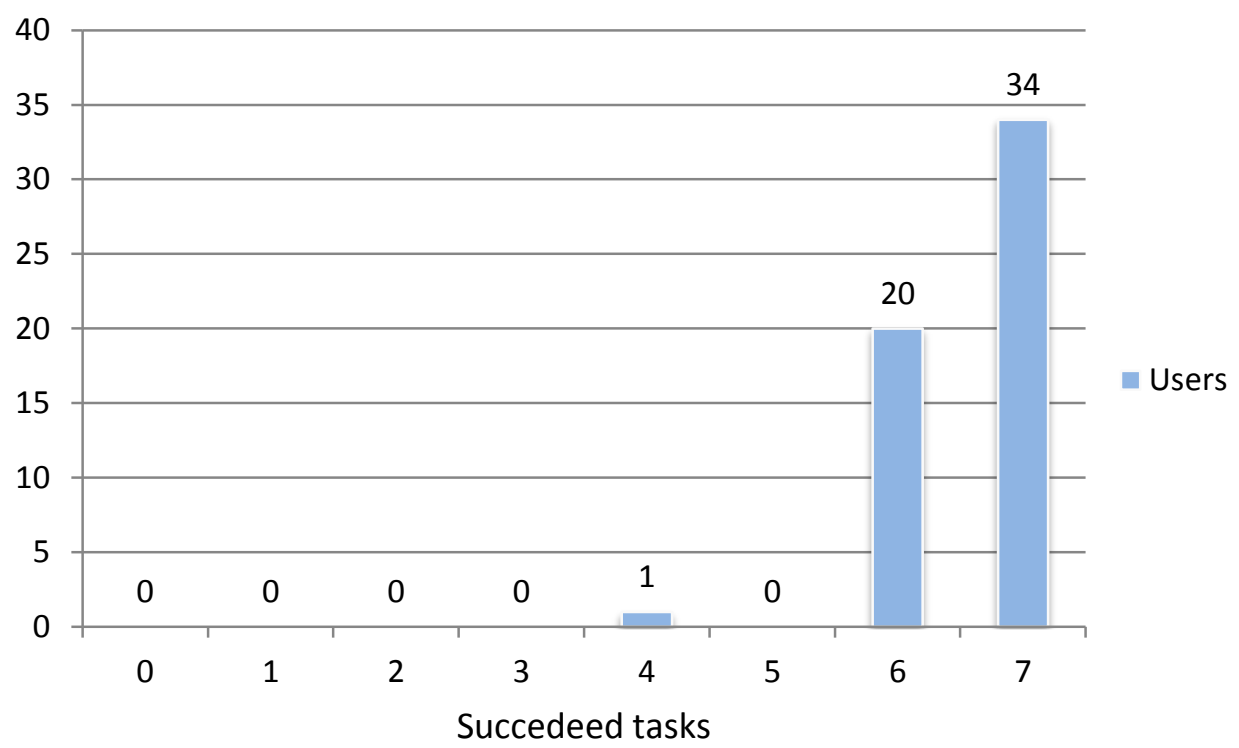

Figure 8. Users grouped by the number of successfully performed tasks.

In Figure 8 we can see a histogram of the number of users able to perform a given number of tasks successfully (ranging from 0 to 7). On one hand, only one user failed in more than one task; and in fact failed in three of the tasks (Long Press, One-Finger Rotation and Scale Down). On the other hand, we can see that $98 \%$ of the users were able to perform 6 or 7 of the evaluated multi-touch gestures.

\subsection{Observational findings}

In addition to the automatic data logging that was performed to measure completion times and degree of success, an external observer gathered valuable information regarding the behavior of children during the experiments. The observer counted the times an issue occurred when it had an impact on the gesture performance in terms of both; success to achieve the task or time needed to achieve the task. These observations revealed different precision issues that will now be described.

The main issue that the external observer reported occurred in the Long Press task in which children have to tap an element with one finger and hold it for a given amount of time to succeed. In this case, children hold their finger on the target but sometimes they perform little undesired movements with their finger which are read by the system as drag events. This precision issue prevents children to complete the task successfully. When this situation occurs, children feel upset, frustrated and make visible their disenchantment with the game by saying that it is not working properly. Right away, they lift their finger from the tablet and retry to succeed in the task by pressing very hard on the target. This makes the task more difficult since the harder they press the more likely to perform undesired drag events. 
Another recurrent situation was the cognitive complexity associated with the process of counting in the double tap interaction. Several children tapped repeatedly on the screen 4 or 5 times even when the target had disappeared instead of only tapping the 2 taps required to succeed in the task. According to educators there are two possible reasons to explain this fact; the first one is that children were unable to count the number of required events whereas others could be able to count but had motor-inhibition problems that prevent them to spot after two taps.

In the gestures which require two contact points to be performed such as Scale up and Scale down the participants who tried to pass the task by using both hands sometimes had some issues since they tend to rest their hand on the surface and this prevented the system to correctly perceive the scale gesture. So, some children experiencing this issue changed their strategy to succeed in the task and used two fingers of the same hand (the index and thumb) pointing out that this strategy was more comfortable for them. In addition, children with DS were not able to estimate the initial distance between their fingers on the surface and could not perform the task with one, or at most two, scale down operations; so they were forced to continuously repeat the following sequence: move fingers together, take fingers off surface, put fingers on surface but close to each other.

Finally, two issues were observed in the rotation task. The first one relative to the performance of the gesture; although the task was designed to be performed only with one contact, two users tried to accomplish the task with two hands preventing them to succeed. The second issue reported was relative to the efficiency when performing the gesture; most of the children rotate the target in clockwise direction despite the fact that sometimes the shortest way to pass the task was to rotate in the anticlockwise direction. This could be because they were right handed and using clockwise rotations they were not occluding the target element with their hands.

Table 7 shows the number of users who had the issues reported above by age group and by gender.

Table 7. Number of users who faced the issues by task, age group and gender.

\begin{tabular}{l|l|r|r}
\hline Task & Age Group & Average & SD \\
\hline \multirow{4}{*}{ Tap } & $5-7$ & 2567.29 & 1663.20 \\
\cline { 2 - 4 } & $8-10$ & 2622.32 & 1883.80 \\
\cline { 2 - 4 } & Total & 2598.31 & 1774.96 \\
\hline \multirow{3}{*}{ Double Tap } & $5-7$ & 3710.33 & 2925.15 \\
\cline { 2 - 4 } & $8-10$ & 3427.32 & 2284.98 \\
\cline { 2 - 4 } & Total & 3550.82 & 2565.25 \\
\hline \multirow{3}{*}{ Long Press } & $5-7$ & 6069.30 & 4760.10 \\
\cline { 2 - 5 } & $8-10$ & 5145.57 & 3308.63 \\
\cline { 2 - 5 } & Total & 5530.46 & 3957.32 \\
\hline \multirow{3}{*}{ Drag } & $5-7$ & 4421.83 & 2579.26 \\
\cline { 2 - 5 } & $8-10$ & 4009.71 & 1297.09 \\
\cline { 2 - 5 } & Total & 4189.55 & 1952.11 \\
\hline \multirow{3}{*}{ Scale Up } & $5-7$ & 2913.63 & 2630.77 \\
\cline { 2 - 5 } & $8-10$ & 4469.16 & 7366.75 \\
\cline { 2 - 5 } & Total & 3790.38 & 5805.46 \\
\hline
\end{tabular}




\begin{tabular}{l|l|r|r}
\hline \multirow{3}{*}{ Scale Down } & $5-7$ & 5935.78 & 4816.01 \\
\cline { 2 - 4 } & $8-10$ & 4806.16 & 3257.19 \\
\cline { 2 - 4 } & Total & 5287.30 & 3994.77 \\
\hline \multirow{3}{*}{ One-Finger Rotation } & $5-7$ & 5467.46 & 3989.47 \\
\cline { 2 - 4 } & $8-10$ & 4557.26 & 2608.09 \\
\cline { 2 - 4 } & Total & 4954.44 & 3281.08 \\
\hline
\end{tabular}

As can be seen, the most usual issues happened with the long press $(55 \%$ of the total observed issues) and the double tap (31\%) tasks. In these cases, the issues were present in both age groups alike. On the other hand, the scales and rotation issues appear less frequently and only in the older age group. Conclusions cannot be drawn about the source of these issues because only two users were involved.

Regarding the occurrence of the issues by gender, there is a balanced distribution of the issues with respect to this factor (see Table 7).

These issues will be discussed below in the context of the interaction aids or design guidelines that application designers should take into account if these touch interactions are included in future applications.

\section{Discussion}

\section{Usability issues and design considerations}

According to the previous results, DS children are able to perform almost all the basic set of multi-touch gestures with high success rates (around 100\%), including gestures such as tap, double tap, drag, scale up, scale down and one-finger rotation. However, some usability problems were already reported as observational findings that need specific design considerations. The entry precision problem of the long press gesture would require an assistive technique that filters these involuntary drag events in order to adapt this gesture to the children actual motor skills. Although the other issues observed reported above (double tap, scale and rotation) did not affect the success rate when performing the gestures, several design strategies could be implemented to help children achieve the tasks in a more efficient way. For example, in the rotation task, the issue about the direction in which children performed the rotation, the application could use graphical semiotics to inform children about the shortest way to achieve the task and prevent them to always use the clockwise option. In addition, in the double tap task, the issue with the number of taps performed by children should be taken into account by designers in order to filter the extra taps performed immediately after a double tap gesture to avoid undesired actions. Finally, with the issue about the estimation of a distance to perform a scale down gesture, designers may consider this and restrict the use of this gesture in their applications if the time to perform a task is an essential requirement. 
Comparing the results with a previous work evaluating the same basic set of gestures with typically developed pre-kindergarten children (aged 2 to 3) (Nacher et al., 2015), several similarities can be seen. In both groups, typically developed pre-kindergarten children and children with DS aged 5 to 10, the results revealed no significant differences among subjects for the success variable with respect to gender or age and that completion time is not affected by gender.

Another similarity is the presence in both groups of usability issues that were already discussed related to the long press, double tap and scale gestures. This is in accordance with previous studies (Pueschel, 2009), revealing that children with DS achieve the same gross motor function at approximately twice the age of typically developed children.

However, in terms of completion time to achieve success, on average pre-kindergarten children needed more time to complete the tap, double tap, long pressed, scale up, drag and one finger rotation gestures. In conclusion, the basic set of multi-touch gestures tested is less demanding for children with DS aged 5 to 10 than for typically developed pre-kindergarteners (aged 2 to 3 ) in terms of the time needed to perform them.

In terms of the effectiveness to interact with multi-touch devices of smaller size than those evaluated in our work, a previous work(Vatavu et al., 2015) with typically developing children aged 3 to 6 showed that they had higher success rates when performing some touch gestures (such as tap, double tap and drag \& drop) with smartphones than with tablet devices. Moreover, the results obtained in the work (Reis and Margarida, 2015) indicate no significant differences in the interaction between smartphones and tablets with a DS boy aged 15. However, the confirmation of these results for DS children aged 5 to 10 would require additional research.

Finally, the results allow designers to follow a design for all approach in which the special needs of children with DS will be supported by the technology transparently (i.e. the interface will adjust to the development level of the users) in an adaptive way.

\section{Threats to validity}

Certain precautions should be taken before extrapolating the results obtained in this study to other contexts. In the case of dynamic gestures, i.e. those that require movement of contact to be performed, success was achieved when passing a certain border. For example, in the drag gesture success was achieved when the target reached the location of the reference with a precision of less than 10 pixels on each $\mathrm{X}$ and $\mathrm{Y}$ axis, but it was not necessary to lift the finger from the screen. In scale gestures success was achieved when passing the border of the target size and in the rotation task success was achieved when passing over the expected orientation. Therefore, no precision was required in the termination phase of the gestures and additional experiments would be needed to verify whether this additional precision requirement would have a significant impact on performance. 
According to (Hinrichs and Carpendale, 2011), there is evidence that some events are affected by previous and subsequent events. Therefore, given that this study tested the gestures in isolation, the obtained results cannot be generalized to scenarios that combine several sequences of different multi-touch gestures.

\section{Conclusions and future work}

In this work we evaluated a basic set of multi-touch gestures (tap, double tap, long press, drag, scale up, scale down and one finger rotation) with 55 DS children in order to find out whether this specific type of user is able to use multi-touch technology and to determine the most suitable gestures for them.

The results obtained show that 5 to 10 year-old DS children are able to perform most of the evaluated multi-touch gestures with success rates close to 100 per cent. Hence, these gestures may be used in future designs of touch-screen applications aimed at these children and would enable designers to fully exploit the power of multi-touch technology to enable richer intuitive and natural interactions.

Only the long press gesture, in which the children scored a 70\% success rate, presented some issues. In this case, the children (mainly the youngest) did not have the required motor skills to press the target and hold their finger on it. An assisted strategy to filter out undesired spurious events at the beginning of the interaction could therefore be included in order to adapt this gesture to the children's actual motor skills.

The results obtained from this work suggest that DS children are able to perform a basic set of multi-touch gestures when no precision is required in the termination phase of the gestures. However, some trends of future work arise and need to be addressed by researchers in the near future. For example, it remains to be explored whether they are able to use these gestures when high levels of accuracy are required in the termination of the gesture. Future work may be carried out to ascertain whether DS children's motor skills fit with applications which require high levels of precision when performing the gestures. In the present study the gestures were evaluated in isolation and more research is needed to determine whether these children are able to perform these multi-touch gestures in sequences.

Another interesting line of work would be the design and evaluation of semiotic approaches to communicate touch gestures to users, such as that proposed by Hiniker et al. (Hiniker et al., 2015) and Nacher et al. (Nacher et al., 2017). These graphical languages could help designers to develop interfaces that inform users of the actions expected of them.

It would also be worth evaluating other complex gestures such as tracing a straight line, horizontal/vertical scroll, circular tracing, etc. and additional principles of design such as Fitt's law. 
Finally, it remains to be studied whether more cognitively complex tasks involving these basic set of gestures may be effectively achieved and whether new defined gestures with specific associated semantics may be learnt by DS children.

\section{References}

Abbeduto, L., Pavetto, M., Kesin, E., Weissman, M.D., Karadottir, S., O'Brien, a, Cawthon, S., 2001. The linguistic and cognitive profile of Down syndrome: evidence from a comparison with fragile X syndrome. Downs. Syndr. Res. Pract. 7, 9-15. doi:10.3104/reports.109

Almeida, G.L., Marconi, N.F., Tortoza, C., Ferreira, M.S., Gottlieb, G.., Corcos, D.., 2000. Sensorimotor deficits in Down syndrome: implications for facilitating motor performance, in: Weeks, D.J., Chua, R., Elliott, E. (Eds.), Perceptual-Motor Behavior in Down Syndrome. Human Kinetics Champaign, IL, pp. 151-174.

Aziz, N.S.A., Ahmad, W.F.W., Zulkifli, J., 2015. User Experience on Numerical Application Between Children with Down Syndrome and Autism. Proceedings of CHI UX Indonesia 2015 (CHIuXiD 2015), pp.26-31.

Basili, V.R., Caldiera, G., Rombach, H.D., 1994. The Goal Question Metric Approach, in: Encyclopedia of Software Engineering. Wiley, pp. 528-532.

Brandão, A., Brandão, L., Nascimento, G., Moreira, B., Vasconcelos, C.N., Clua, E., 2010. JECRIPE: stimulating cognitive abilities of children with Down Syndrome in pre-scholar age using a game approach. Proc. 7th Int. Conf. Adv. Comput. Entertain. Technol. (ACE 2010) 15-18. doi:http://dx.doi.org/10.1145/1971630.1971635

Bruni, M., 2006a. Gross Motor Skills for Children with Down Syndrome. Woodbine House, Bethesda.

Bruni, M., 2006b. Fine motor skills for children with Down syndrome. Woodbine House, Bethesda, MD.

Bull, M.J., 2011. Health Supervision for Children With Down Syndrome. Pediatrics 128, 393406. doi:10.1542/peds.2011-1605

Buxton, B., 2013. Multi-touch systems that I have known and loved [WWW Document]. URL http://billbuxton.com/multitouchOverview.html

Carr, J., 1985. The development of intelligence, Current Approaches to Down's Syndrome. London.

Chapman, R.S., 1997. Language development in children and adolescents with Down syndrome. Ment. Retard. Dev. Disabil. Res. Rev. 3, 307-312. doi:10.1002/(SICI)10982779(1997)3:4<307::AID-MRDD5>3.0.CO;2-K

Cohen, W.I., 2003. Health Care Guidelines for Individuals with Down Syndrome-1999 Revision, in: Down Syndrome. John Wiley \& Sons, Inc., New York, USA, pp. 237-245. doi:10.1002/0471227579.ch17

Connolly, B.H., Michael, B.T., 1986. Performance of Retarded Children, With and Without Down Syndrome, on the Bruininks Oseretsky Test of Motor Proficiency. Phys. Ther. 66, 344-348.

De Haan, G., 2013. A vision of the future of media technology design education - design and education from HCI to UbiComp. Proc. 13th Comput. Sci. Educ. Res. Conf. 67-73.

Dulaney, C.L., Tomporowski, P.D., 2000. Attention and cognitive-skill acquisition, in: Perceptual-Motor Behavior in Down Syndrome. Human Kinetics Champaign, IL, pp. 175197. 
Feng, J., Lazar, J., Kumin, L., Ozok, A., 2010. Computer Usage by Children with Down Syndrome: Challenges and Future Research. ACM Trans. Access. Comput. 2, 1-44. doi:10.1145/1714458.1714460

Feng, J., Lazar, J., Kumin, L., Ozok, a, 2008. Computer Usage by Young Individuals with Down Syndrome: An Exploratory Study. Proc. 10th Int. ACM SIGACCESS Conf. Comput. Access. 35-42. doi:10.1145/1414471.1414480

Fernández-López, Á., Rodríguez-Fórtiz, M.J., Rodríguez-Almendros, M.L., Martínez-Segura, M.J., 2013. Mobile learning technology based on iOS devices to support students with special education needs. Comput. Educ. 61, 77-90. doi:10.1016/j.compedu.2012.09.014

Frank, K., Esbensen, A.J., 2015. Fine motor and self-care milestones for individuals with Down syndrome using a Retrospective Chart Review. J. Intellect. Disabil. Res. 59, 719-729. doi:10.1111/jir.12176

Gao, Q., Sun, Q., 2015. Examining the Usability of Touch Screen Gestures for Older and Younger Adults. Hum. Factors J. Hum. Factors Ergon. Soc. 57, 835-863. doi: $10.1177 / 0018720815581293$

Garzotto, F., Gonella, R., 2011. An open-ended tangible environment for disabled children's learning, in: Proceedings of the 10th International Conference on Interaction Design and Children - IDC '11. ACM Press, New York, New York, USA, pp. 52-61. doi:10.1145/1999030.1999037

Groden, G., 1969. Relationships between intelligence, simple, and complex motor proficiency. Am. J. Ment. Defic. 74, 373-375.

Hardy, L.L., King, L., Farrell, L., Macniven, R., Howlett, S., 2010. Fundamental movement skills among Australian preschool children. J. Sci. Med. Sport 13, 503-508. doi:10.1016/j.jsams.2009.05.010

Haro, B.P.M., Santana, P.C., Magaña, M. a., 2012. Developing reading skills in children with Down syndrome through tangible interfaces. Proc. 4th Mex. Conf. Human-Computer Interact. - MexIHC '12 28. doi:10.1145/2382176.2382183

Hayden, F.J., 1964. Physical fitness for the mentally retarded: A manual for teachers and parents. Frank Hayden, London.

Henderson, S.E., 1985. Motor skill development, in: Current Approaches to Down's Syndrome. D. Lane \& B. Stratford, London: Holt, Rinehart and Winston, pp. 187-218.

Hiniker, A., Sobel, K., Hong, S.R., Suh, H., Irish, I., Kim, D., Kientz, J. a., 2015. Touchscreen Prompts for Preschoolers: Designing Developmentally Appropriate Techniques for Teaching Young Children to Perform Gestures. Proc. 14th Int. Conf. Interact. Des. Child. 109-118. doi:10.1145/2771839.2771851

Hinrichs, U., Carpendale, S., 2011. Gestures in the wild: studying multi-touch gesture sequences on interactive tabletop exhibits, in: Annual Conference on Human Factors in Computing Systems (CHI'11). ACM Press, New York, New York, USA, pp. 3023-3032. doi:10.1145/1978942.1979391

Hourcade, J.P., Bullock-Rest, N.E., Hansen, T.E., 2011. Multitouch tablet applications and activities to enhance the social skills of children with autism spectrum disorders. Pers. Ubiquitous Comput. 16, 157-168. doi:10.1007/s00779-011-0383-3

Jadan-Guerrero, J., Jaen, J., Carpio, M. a., Guerrero, L. a., 2015. Kiteracy: A Kit of Tangible Objects to Strengthen Literacy Skills in Children with Down Syndrome. Proc. 14th Int. Conf. Interact. Des. Child. - IDC'15 315-318. doi:10.1145/2771839.2771905

Johnson, L., Adams, S., Cummins, M., 2012. The NMC Horizon Report: 2012 K-12. The New Media Consortium, Austin, Texas. 
Kirijian, a, Myers, M., Charland, S., 2007. Web fun central: online learning tools for individuals with Down syndrome, Universal Usability: Designing Information Systems for Diverse User Populations. John Wiley \& Sons, Chichester, UK.

Kumin, L., 2003. Early Communication Skills in Children with Down Syndrome: A Guide for Parents and Professionals. Woodbine House, Bethesda.

Kumin, L., Lazar, J., 2012. A Usability Evaluation of Workplace-Related Tasks on a MultiTouch Tablet Computer by Adults with Down Syndrome. J. Usability ... 7, 118-142.

Lauteslager, P.E.M., 2004. Children with Down's Syndrome. Motor Development and Intervention. Heeren Loo Zorggroep, Amesfoort, the Netherlands.

Lazar, J., Kumin, L., Feng, J.H., 2011. Understanding the computer skills of adult expert users with down syndrome. Proc. 13th Int. ACM SIGACCESS Conf. Comput. Access. ASSETS '11 51. doi:10.1145/2049536.2049548

Levine, S.C., Huttenlocher, J., Taylor, A., Langrock, A., 1999. Early sex differences in spatial skill. Dev. Psychol. 35, 940-949. doi:10.1037/0012-1649.35.4.940

Malak, R., Kotwicka, M., Krawczyk-Wasielewska, A., Mojs, E., Samborski, W., 2013. Motor skills, cognitive development and balance functions of children with Down syndrome. Ann. Agric. Environ. Med. 20, 803-6.

Markopoulos, P., Bekker, M., 2003. Interaction design and children. Interact. Comput. 15, 141149. doi:10.1016/S0953-5438(03)00004-3

Memisevic, H., Macak, A., 2014. Fine motor skills in children with Down syndrome. Spec. Edukac. i Rehabil. 13, 365-377. doi:10.5937/specedreh13-7465

Mihajlov, M., Law, E.L.-C., Springett, M., 2014. Intuitive Learnability of Touch Gestures for Technology-Naive Older Adults. Interact. Comput. 27, 344-356. doi:10.1093/iwc/iwu044

Moser, T., Reikerås, E., 2016. Motor-life-skills of toddlers - a comparative study of Norwegian and British boys and girls applying the Early Years Movement Skills Checklist. Eur. Early Child. Educ. Res. J. 24, 115-135. doi:10.1080/1350293X.2014.895560

Nacher, Vicente;Jaen, Javier;Navarro, Elena;Catala, Alejandro;González, P., 2015. Multi-touch gestures for pre-kindergarten children. Int. J. Hum. Comput. Stud. 73, 37-51. doi:10.1016/j.ijhes.2014.08.004

Nacher, V., Jaen, J., Catala, A., 2017. Evaluating Multitouch Semiotics to Empower Prekindergarten Instruction with Interactive Surfaces. Interact. Comput. 29, 97-116. doi:10.1093/iwc/iww007

Nacher, V., Jaen, J., Catala, A., Navarro, E., Gonzalez, P., 2014. Improving Pre-Kindergarten Touch Performance, in: Proceedings of the Ninth ACM International Conference on Interactive Tabletops and Surfaces - ITS '14. ACM Press, New York, New York, USA, pp. 163-166. doi:10.1145/2669485.2669498

Ortega-Tudela, J.M., Gómez-Ariza, C.J., 2006. Computer-assisted teaching and mathematical learning in Down Syndrome children. J. Comput. Assist. Learn. 22, 298-307. doi:10.1111/j.1365-2729.2006.00179.x

Pangalos, C., Avramopoulos, D., Blouin, J.L., Raoul, O., deBlois, M.C., Prieur, M., Schinzel, A.A., Gika, M., Abazis, D., Antonarakis, S.E., 1994. Understanding the mechanism(s) of mosaic trisomy 21 by using DNA polymorphism analysis. Am. J. Hum. Genet. 54, 473-81.

Parker, S.E., Mai, C.T., Canfield, M.A., Rickard, R., Wang, Y., Meyer, R.E., Anderson, P., Mason, C.A., Collins, J.S., Kirby, R.S., Correa, A., 2010. Updated National Birth Prevalence estimates for selected birth defects in the United States, 2004-2006. Birth Defects Res. A. Clin. Mol. Teratol. 88, 1008-16. doi:10.1002/bdra.20735 
Peter, C., Crane, E., Fabri, M., Agius, H., Axelrod, L., 2008. Emotion in HCI: designing for people. Proc. 22nd Br. HCI Gr. Annu. Conf. People Comput. Cult. Creat. Interact. - Vol. 2 189-190.

Piaget, J., 1973. The Child and Reality. Grossman, New York.

Piper, A.M., O’Brien, E., Morris, M.R., Winograd, T., 2006. SIDES: a cooperative tabletop computer game for social skills development, in: 20th Anniversary Conference on Computer Supported Cooperative Work (CSCW'06). ACM Press, New York, New York, USA, pp. 1-10. doi:10.1145/1180875.1180877

Plowman, L., 2015. Researching Young Children's Everyday Uses of Technology in the Family Home. Interact. Comput. 27, 36-46. doi:10.1093/iwc/iwu031

Pueschel, S.M., 2009. A Parent's Guide to Down Syndrome. Wydawnictwo Replika, Zakrzewo.

Reis, S., Margarida, A., 2015. A comparative analysis of using two mobile touch devices (ipad ${ }^{\circledR}$ and iphone $\left.{ }^{\circledR}\right)$ by an adolescent with down syndrome. Prism. Soc. Rev. Investig. Soc. 415-439.

Rubio, G., Navarro, E., Montero, F., 2012. APADYT: a multimedia application for SEN learners. Multimed. Tools Appl. doi:10.1007/s11042-012-1304-9

Shin, M., Besser, L.M., Kucik, J.E., Lu, C., Siffel, C., Correa, A., 2009. Prevalence of Down syndrome among children and adolescents in 10 regions of the United States. Pediatrics 124, 1565-71. doi:10.1542/peds.2009-0745

Smith, A.L., Chaparro, B.S., 2015. Smartphone Text Input Method Performance, Usability, and Preference With Younger and Older Adults. Hum. Factors J. Hum. Factors Ergon. Soc. 57, 1015-1028. doi:10.1177/0018720815575644

Smith, S.P., Burd, E., Rick, J., 2012. Developing, evaluating and deploying multi-touch systems. Int. J. Hum. Comput. Stud. 70, 653-656. doi:10.1016/j.ijhcs.2012.07.002

Vatavu, R., Cramariuc, G., Schipor, D.M., 2015. Touch interaction for children aged 3 to 6 years : Experimental findings and relationship to motor skills. Int. J. Hum. Comput. Stud. 74, 54-76. doi:10.1016/j.ijhes.2014.10.007

Vicari, S., 2006. Motor development and neuropsychological patterns in persons with Down syndrome. Behav. Genet. 36, 355-364. doi:10.1007/s10519-006-9057-8

Weijerman, M.E., de Winter, J.P., 2010. Clinical practice: The care of children with Down syndrome. Eur. J. Pediatr. 169, 1445-1452. doi:10.1007/s00431-010-1253-0

Weiss, P.L., Gal, E., Eden, S., Zancanaro, M., Telch, F., 2011. Usability of a Multi-Touch Tabletop Surface to Enhance Social Competence Training for Children with Autism Spectrum Disorder, in: Chais Conference on Instructional Technologies Research 2011: Learning in the Technological Era (CHAIS 2011). The Open University of Israel, pp. 7178.

Wishart, J.G., 1993. The development of learning difliculties in children with Down's syndrome. J. Intellect. Disabil. Res. 37, 389-403. doi:10.1111/j.1365-2788.1993.tb00882.x 


\section{Appendix A}

Table 8. Completion time in milliseconds in each task by age group.

\begin{tabular}{l|l|r|r}
\hline Task & Age Group & Average & SD \\
\hline \multirow{4}{*}{ Tap } & $5-7$ & 2567.29 & 1663.20 \\
\cline { 2 - 4 } & $8-10$ & 2622.32 & 1883.80 \\
\cline { 2 - 4 } & Total & 2598.31 & 1774.96 \\
\hline \multirow{3}{*}{ Double Tap } & $5-7$ & 3710.33 & 2925.15 \\
\cline { 2 - 4 } & $8-10$ & 3427.32 & 2284.98 \\
\cline { 2 - 4 } & Total & 3550.82 & 2565.25 \\
\hline \multirow{3}{*}{ Drag } & $5-7$ & 6069.30 & 4760.10 \\
\cline { 2 - 4 } & $8-10$ & 5145.57 & 3308.63 \\
\cline { 2 - 4 } & Total & 5530.46 & 3957.32 \\
\hline \multirow{3}{*}{ Scale Up } & $5-7$ & 4421.83 & 2579.26 \\
\cline { 2 - 5 } & $8-10$ & 4009.71 & 1297.09 \\
\cline { 2 - 5 } & Total & 4189.55 & 1952.11 \\
\hline \multirow{3}{*}{ Scale Down } & $5-7$ & 2913.63 & 2630.77 \\
\cline { 2 - 5 } & $8-10$ & 4469.16 & 7366.75 \\
\cline { 2 - 5 } & Total & 3790.38 & 5805.46 \\
\hline \multirow{3}{*}{ One-Finger Rotation } & $5-7$ & 5935.78 & 4816.01 \\
\cline { 2 - 5 } & $8-10$ & 4806.16 & 3257.19 \\
\cline { 2 - 5 } & Total & 5287.30 & 3994.77 \\
\hline & $5-7$ & 5467.46 & 3989.47 \\
\cline { 2 - 5 } & $8-10$ & 4557.26 & 2608.09 \\
\cline { 2 - 5 } & Total & 4954.44 & 3281.08 \\
\hline
\end{tabular}

Table 9. Completion time in milliseconds in each task by gender.

\begin{tabular}{|c|c|c|c|}
\hline Task & Gender & Average & SD \\
\hline \multirow{3}{*}{ Tap } & $\mathrm{F}$ & 2984.71 & 2070.64 \\
\hline & $\mathrm{M}$ & 2299.16 & 1473.72 \\
\hline & Total & 2598.31 & 1774.96 \\
\hline \multirow{3}{*}{ Double Tap } & $\mathrm{F}$ & 3389.04 & 2367.89 \\
\hline & $\mathrm{M}$ & 3685.63 & 2746.48 \\
\hline & Total & 3550.82 & 2565.25 \\
\hline \multirow{3}{*}{ Long Press } & $\mathrm{F}$ & 5899.35 & 4721.84 \\
\hline & $\mathrm{M}$ & 5191.08 & 3159.12 \\
\hline & Total & 5530.46 & 3957.32 \\
\hline \multirow{3}{*}{ Drag } & $\mathrm{F}$ & 4547.84 & 2506.58 \\
\hline & $\mathrm{M}$ & 3890.97 & 1301.27 \\
\hline & Total & 4189.55 & 1952.11 \\
\hline \multirow{3}{*}{ Scale Up } & $\mathrm{F}$ & 2842.68 & 3940.05 \\
\hline & $\mathrm{M}$ & 4580.13 & 6963.55 \\
\hline & Total & 3790.38 & 5805.46 \\
\hline \multirow{3}{*}{ Scale Down } & $\mathrm{F}$ & 5554.68 & 4624.16 \\
\hline & $\mathrm{M}$ & 5056.79 & 3429.22 \\
\hline & Total & 5287.30 & 3994.77 \\
\hline \multirow{3}{*}{ One-Finger Rotation } & $\mathrm{F}$ & 5483.92 & 3579.14 \\
\hline & $\mathrm{M}$ & 4513.20 & 3000.24 \\
\hline & Total & 4954.44 & 3281.08 \\
\hline
\end{tabular}


Table 10. Success rate in each task by age group.

\begin{tabular}{l|l|c|r}
\hline Task & Age Group & Average & SD \\
\hline \multirow{4}{*}{ Tap } & $5-7$ & 100.00 & 0.00 \\
\cline { 2 - 4 } & $8-10$ & 100.00 & 0.00 \\
\cline { 2 - 4 } & Total & 100.00 & 0.00 \\
\hline \multirow{3}{*}{ Louble tap } & $5-7$ & 95.83 & 4.17 \\
\cline { 2 - 4 } & $8-10$ & 100.00 & 0.00 \\
\cline { 2 - 4 } & Total & 98.18 & 1.82 \\
\hline \multirow{3}{*}{ Drag } & $5-7$ & 54.17 & 10.39 \\
\cline { 2 - 4 } & $8-10$ & 80.65 & 7.21 \\
\cline { 2 - 4 } & Total & 69.09 & 6.29 \\
\hline \multirow{3}{*}{ Scale up } & $5-7$ & 100.00 & 0.00 \\
\cline { 2 - 4 } & $8-10$ & 100.00 & 0.00 \\
\cline { 2 - 4 } & Total & 100.00 & 0.00 \\
\hline \multirow{3}{*}{ Scale down } & $5-7$ & 100.00 & 0.00 \\
\cline { 2 - 4 } & $8-10$ & 96.77 & 3.22 \\
\cline { 2 - 4 } & Total & 98.18 & 1.82 \\
\hline \multirow{3}{*}{ One-Finger Rotation } & $5-7$ & 95.83 & 3.33 \\
\cline { 2 - 4 } & $8-10$ & 100.00 & 0.00 \\
\cline { 2 - 4 } & Total & 98.18 & 1.82 \\
\hline & $5-7$ & 91.67 & 5.76 \\
\cline { 2 - 4 } & $8-10$ & 96.78 & 3.22 \\
\cline { 2 - 4 } & Total & & 3.09 \\
\hline
\end{tabular}

Table 11. Success rate in each task by gender.

\begin{tabular}{|c|c|c|c|}
\hline Task & Gender & Average & SD \\
\hline \multirow{3}{*}{ Tap } & $\mathrm{F}$ & 100.00 & 0.00 \\
\hline & $\mathrm{M}$ & 100.00 & 0.00 \\
\hline & Total & 100.00 & 0.00 \\
\hline \multirow{3}{*}{ Double tap } & $\mathrm{F}$ & 96.00 & 4.00 \\
\hline & $\mathrm{M}$ & 100.00 & 0.00 \\
\hline & Total & 98.18 & 1.82 \\
\hline \multirow{3}{*}{ Long Press } & $\mathrm{F}$ & 72.00 & 9.17 \\
\hline & $\mathrm{M}$ & 66.67 & 8.75 \\
\hline & Total & 69.09 & 6.29 \\
\hline \multirow{3}{*}{ Drag } & +2 & 100.00 & 0.00 \\
\hline & $\mathrm{M}$ & 100.00 & 0.00 \\
\hline & Total & 100.00 & 0.00 \\
\hline \multirow{3}{*}{ Scale up } & $\mathrm{F}$ & 100.00 & 0.00 \\
\hline & $\mathrm{M}$ & 96.67 & 3.33 \\
\hline & Total & 98.18 & 1.82 \\
\hline \multirow{3}{*}{ Scale down } & $\mathrm{F}$ & 100.00 & 0.00 \\
\hline & $\mathrm{M}$ & 96.67 & 4.17 \\
\hline & Total & 98.18 & 1.82 \\
\hline \multirow{3}{*}{ One-Finger rotation } & $\mathrm{F}$ & 92.00 & 5.54 \\
\hline & $\mathrm{M}$ & 96.67 & 3.33 \\
\hline & Total & 94.55 & 3.09 \\
\hline
\end{tabular}

